\title{
A cross-sectional study on awareness and perception about basic life support/ cardio-pulmonary resuscitation among undergraduate medical students from coastal South India
}

Harsha Kumar H. N., Swasthik Upadhya P., Shruthi Ashok P., Akhil Chowdari G., Niranjan G.M., Dinesh B.

Department of Community Medicine, Kasturba Medical College, Mangalore, Karnataka,

India

Address for the Correspondence: Dr. Harsha Kumar H. N., Associate Prof, Department of Community Medicine, Kasturba Medical College

(Manipal University), Near Hampanakatta, Mangalore - 575 001, Karnataka, India. E-mail: drhnhk@rediffmail.com

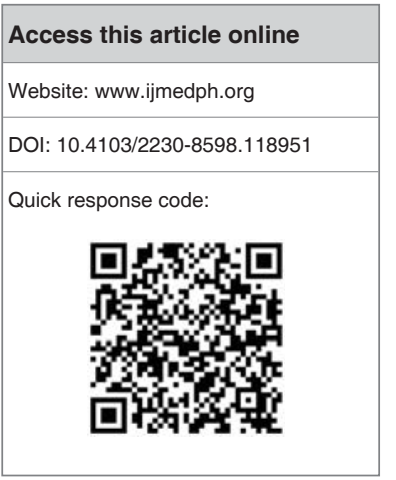

Background: Basic Life Support (BLS)/Cardiopulmonary Resuscitation (CPR) is an important part of emergency medical care. This study is done among medical undergraduate students, to know their knowledge and perceptions about BLS, as they are going to face such situations in future, as doctors. Materials and Methods: A questionnaire-based study was conducted among 377 medical undergraduate students. The questionnaire included the following parts: (1) Basic characteristics of the study participants, (2) Knowledge about BLS/CPR, (3) Perceptions about BLS/CPR. The components of knowledge and perception based questions were scored. The data was analyzed using SPSS version 12. Results were expressed as proportions in appropriate tables and graphs. Student's Independent ' $t$ ' test was used to compare means between students who had undergone previous training if any and those who had no such training. Results: Out of 377 students, majority $(84.6 \%)$ had heard of BLS/CPR. Some of them $(30.6 \%)$ could give the correct order of performing CPR as per the AHA guidelines (Year 2010). Few (18.9\%) had undergone prior training in BLS, whereas, only $17.7 \%$ had been in a situation that needed BLS/CPR. Nearly half $(50.2 \%)$ were not confident of performing BLS/CPR. Comparison of the students revealed that students who had training had higher mean scores for 'response to a situation needing BLS/CPR' and 'signs of successful resuscitation', though there was little difference in their knowledge of 'indications for BLS/CPR. Overall perception was not favourable and the students were not confident of performing BLS/CPR. Conclusions: The students need to be taught and trained in the CPR/BLS early in the curriculum to improve their knowledge. Repeated training would increase their confidence.

Key words: Basic life support/cardiopulmonary resuscitation, Medical student's, knowledge and perception

\section{INTRODUCTION}

Training in Emergency Medical Services is reported to be poor in India. ${ }^{[1]}$ There is a shortage of emergency medical professionals in India. ${ }^{[2]}$ As such, a Master's degree in Emergency Medicine is not offered in most of the medical colleges in India. Hence, most of the emergencies are handled by doctors working in casualties of various private and government hospitals. ${ }^{[1]}$ An appropriate response in an emergency situation depends on good technical knowledge, which decides the patient's outcome. ${ }^{[3]}$ Therefore, teaching medical students and training doctors in emergency care is essential.

Basic life support (BLS)/Cardiopulmonary Resuscitation (CPR) is a part of emergency medical care. Timely provision of BLS/CPR saves lives. Low confidence among medical students in performing BLS has been reported from Europe. ${ }^{[4]}$ Poor training among undergraduate medical students has also been reported from UK and Poland. ${ }^{[5,6]}$ Inadequate knowledge of BLS has been reported from Switzerland and Pakistan. ${ }^{[7,8]}$ 
A study from South India reports poor knowledge of BLS among medical undergraduate students. ${ }^{[9]}$ Usually BLS/CPR is taught in the final year of the medical curriculum in India. Few classes as a part of the curriculum to teach BLS/CPR do not seem to be adequate. This can be inferred from the review of the studies cited above. Therefore, additional training of the medical students for providing BLS/CPR is essential. Studies that explore the knowledge about BLS/CPR help in understanding the training needs and devising learning objectives for a BLS course. It also helps us to know the student's perceptions about BLS. So this study was undertaken with an objective to Know (1) The knowledge of BLS and (2) Perceptions about BLS among undergraduate medical students.

\section{MATERIALS AND METHODS}

\section{Background}

Kasturba Medical College, affiliated to Manipal University, has an annual intake of 250 students. The students are posted to hospitals starting from the second year of MBBS. These teaching hospitals attached to the college are referral tertiary care centers. Students are taught BLS/CPR only in the final year of the course, as a part of the curriculum.

\section{Study design and sample size}

This is a questionnaire based cross-sectional study. All the undergraduate medical students from first to final year of MBBS were considered for the study. We assumed that at least $50 \%$ of the medical students would have heard of the term 'Basic Life Support (BLS)/Cardiopulmonary Resuscitation (CPR)'. Using the formula for infinite population, that is, $\mathrm{N}=\mathrm{Z}^{2} \mathrm{PQ} / \mathrm{d}^{2}$, for $95 \%$ confidence intervals, at $85 \%$ power, a sample of 171 was computed. Accounting for a $10 \%$ non-response, the total sample size of 190 was arrived at. Any number of students above this minimum needed was considered adequate.

\section{Study instrument development and pre-testing}

A semi-structured anonymous questionnaire was developed to obtain the following components of information: (1) Basic characteristics of the study participants. (2) Knowledge about BLS/CPR: The questions were based on the guidelines of the American Heart Association. ${ }^{[10]}$ (3) Perceptions about BLS/CPR. There were statements exploring their perceptions, which were graded on a five-point Likert scale (strongly disagree to strongly agree). This questionnaire was pretested. Based on the results of pretesting, certain changes were made. Some questions were changed to closed ended and some to open-ended. The order of the questions was changed. The final questionnaire had the following categories of questions about the knowledge of BLS ( $n=$ number of questions): (1) Indications for BLS [6]; (2) Response to a situation needing BLS [8]; (3) Order of performing BLS [1]; (4) Signs of successful resuscitation [4]; and (5) Setting where BLS is performed [3]. For each knowledge question depicting a series of responses to a hypothetical real life situation, Options of 'yes', 'no', and 'don't know' were provided. These responses were scored on a scale of two to zero. Thus, the range of maximum scores for the various components were as follows (Maximum score - Minimum score): Indications for BLS (12-0), Response to a situation needing BLS (16-0), Signs for successful resuscitation (8-0). There were five perception-related statements. The total scores for perceptions ranged from Zero 0-28.

\section{Data collection}

Permission was obtained from the Institutional Ethics Committee to conduct the study. Permission was obtained from the Dean of the college to approach the students in the classrooms. The purpose of the study was explained. It was made clear that the participation was voluntary. For those who did not want to participate, there was a provision to write the reasons for the same on the questionnaire. Twenty minutes were allotted for them to respond. The collected questionnaires were analyzed.

\section{Data analysis}

The data was analyzed using SPSS Version 12. The results were expressed as proportions, in appropriate tables. The mean scores, along with their standard deviations were computed for various knowledge categories and overall perceptions. A score of less than $50 \%$ for that knowledge category was considered inadequate. Similarly a score of $<14$ was considered as a negative perception. Comparisons were made between students who had undergone previous training, if any, and those who had no such training. The Student's independent ' $P$ ' test was the test of significance used. $P<0.05$ was considered significant.

\section{RESULTS}

A total of 377 students participated in the study. The proportion of males $(53.3 \%)$ was slightly higher than females (46.7\%). The breakup of the number of the students for each is as follows [n (\%)]: First year [95 (25.2\%)], Second year [95 (25.2\%)], Third year [94 (24.9\%)], Final year [93 (24.7\%)]. Majority (84.6\%) had heard of BLS/CPR.

Students did not have proper knowledge about the 'indications for BLS/CPR,' the results of which are presented in Table 1. Similarly the results pertaining to 'response to a situation that needs BLS/CPR' and 'signs of successful resuscitation' are presented in Tables 2 and 3 , respectively, indicate that the students had good overall awareness. Airway Breathing Circulation (ABC) was the order familiar to majority $(46.8 \%)$ of the students, even though the recent guidelines state $\mathrm{CAB}$ which was known to only $30.6 \%$. Rest (22.6\%) had given wrong responses. Majority $(77.3 \%)$ of the students were aware that BLS/CPR was not limited to only hospital settings and that it could be performed anywhere. Some $(33.3 \%)$ of the students had seen a CPR being performed. Few students (18.9\%) had undergone prior training in BLS. About $17.7 \%$ of the students had been in a situation that needed BLS/CPR, although only $8.3 \%$ had attempted to provide BLS/CPR. Most (70.7\%) of the students knew the correct emergency ambulance helpline number. 


\begin{tabular}{|c|c|}
\hline Indication & Number (\%) \\
\hline \multicolumn{2}{|c|}{$\begin{array}{l}\text { Unconscious person with no palpable pulses and no } \\
\text { respiration }(n=313)\end{array}$} \\
\hline Yes & $264(84.3)$ \\
\hline No & $29(9.3)$ \\
\hline Don't know & $20(6.4)$ \\
\hline \multicolumn{2}{|c|}{$\begin{array}{l}\text { Victim of road traffic accident with multiple } \\
\text { injuries }(n=296)\end{array}$} \\
\hline Yes & $88(29.7)$ \\
\hline No & $148(50.0)$ \\
\hline Don't know & $60(20.3)$ \\
\hline \multicolumn{2}{|c|}{$\begin{array}{l}\text { Unresponsive person with normal pulse and } \\
\text { respiration }(n=299)\end{array}$} \\
\hline Yes & $113(37.8)$ \\
\hline No & $133(44.5)$ \\
\hline Don't know & $53(17.7)$ \\
\hline \multicolumn{2}{|c|}{ Victim of drowning $(n=308)$} \\
\hline Yes & $260(84.4)$ \\
\hline No & $28(9.1)$ \\
\hline Don't know & $20(6.5)$ \\
\hline \multicolumn{2}{|c|}{ Burns victim ( $n=293$ ) } \\
\hline Yes & $58(19.8)$ \\
\hline No & $167(57.0)$ \\
\hline Don't know & $68(23.2)$ \\
\hline \multicolumn{2}{|l|}{ Choking $(n=301)$} \\
\hline Yes & 129 (42.9) \\
\hline No & $115(38.2)$ \\
\hline Don't know & $57(18.9)$ \\
\hline \multicolumn{2}{|c|}{ Total scores for knowledge about indications (12-0) } \\
\hline Adequate $(\geq 7)$ & $165(43.8)$ \\
\hline Inadequate $(\leq 6)$ & $212(56.2)$ \\
\hline
\end{tabular}

Most (50.2\%) of the students were not confident of performing BLS/CPR and would be uncomfortable to be in a situation that needed BLS/CPR, which are presented in Table 4. Comparison of the students who got trained with those who did not have any training [Table 5], revealed that students who had training had higher mean scores for 'response to a situation needing BLS/CPR' and 'signs of successful resuscitation'. These differences were statistically significant [Table 5]. However, training made little difference in their knowledge of 'indications for BLS/CPR' and the overall perception. Most of the students were not confident and or comfortable to perform BLS/CPR [Table 5].

Most (93.7\%) of them were interested in learning BLS/CPR.

\section{DISCUSSION}

As 377 students participated in the study and the majority (84.6\%) of the students had heard of BLS/CPR, the sample size was considered adequate for the interpretation of results. As we had studied knowledge according to separate components like, Indications, Response to a Situation, and Signs of Successful Resuscitation, we could not find comparative data on these aspects from the

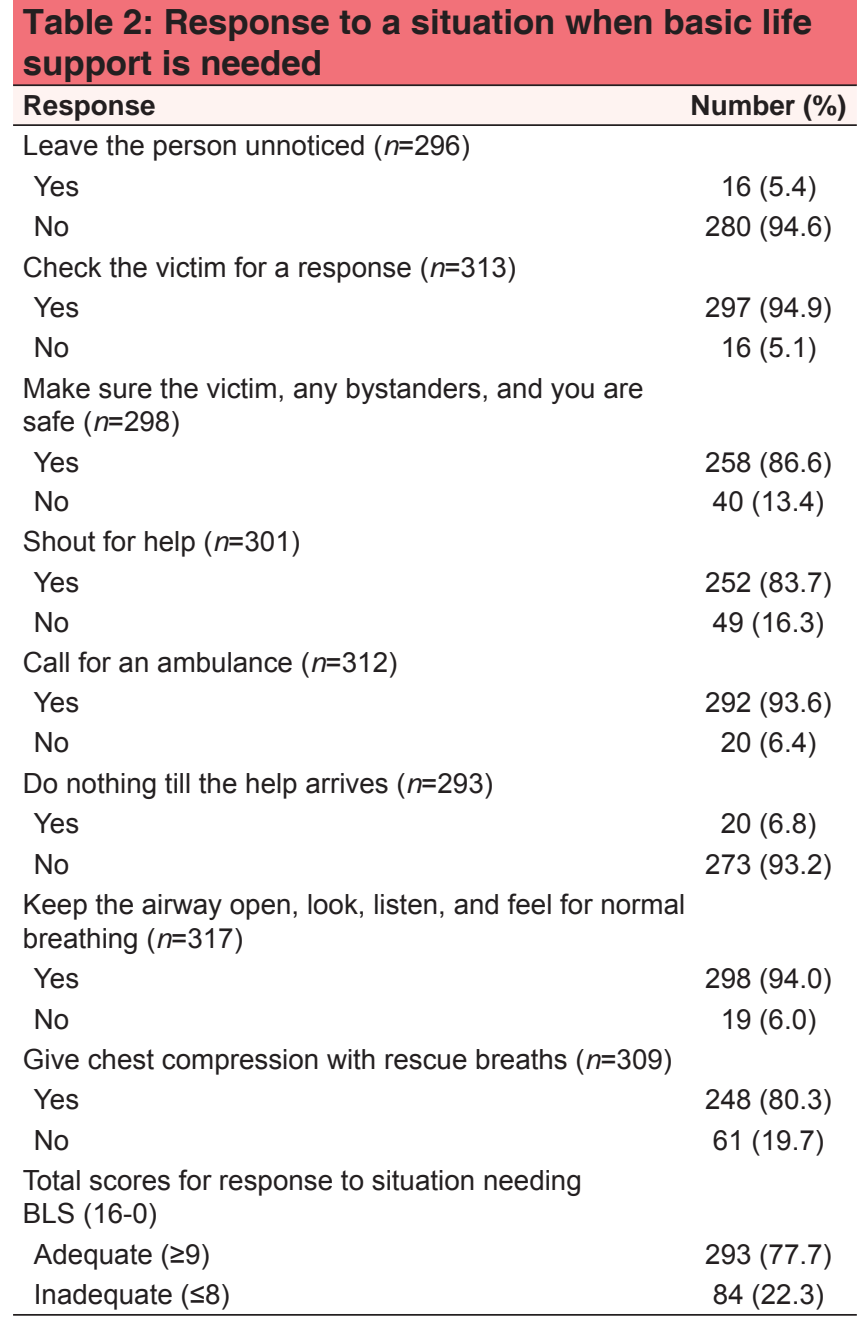

previous published reports. For example, the only study from India (Pondicherry) reports that $85 \%$ had obtained $<50 \%$ marks without providing any specific information about the components. ${ }^{[10]}$ Moreover, their study sample consisted of students from medical, dental, nursing, and homeopathy colleges, apart from doctors, which makes the comparison inappropriate..$^{[9]}$

Majority (84.6\%) of the students had heard of BLS/CPR. But lack of knowledge about indications for CPR could be inferred from that fact that about $37.8 \%$ felt that CPR should be administered to an unconscious person with normal palpable pulses and respiration [Table 1], and 39.5\% only knew the correct order for performing CPR. The results reflect that students had adequate overall understanding about the 'response to a situation where CPR is needed' and 'signs of successful resuscitation'. Less than half $(48.1 \%)$ of the students from Switzerland could give correct answers on knowledge based questions. ${ }^{[7]}$ Similarly low levels $(54.3 \%$, and $25 \%$ ) of knowledge have been reported from medical students in Poland and interns from southern India, respectively. ${ }^{[6,11]}$ The apparent good knowledge observed in our study about 'response to a situation,' and 'signs of successful resuscitation' probably reflects 'guesswork/commonsense'. As the study subjects consist of students 


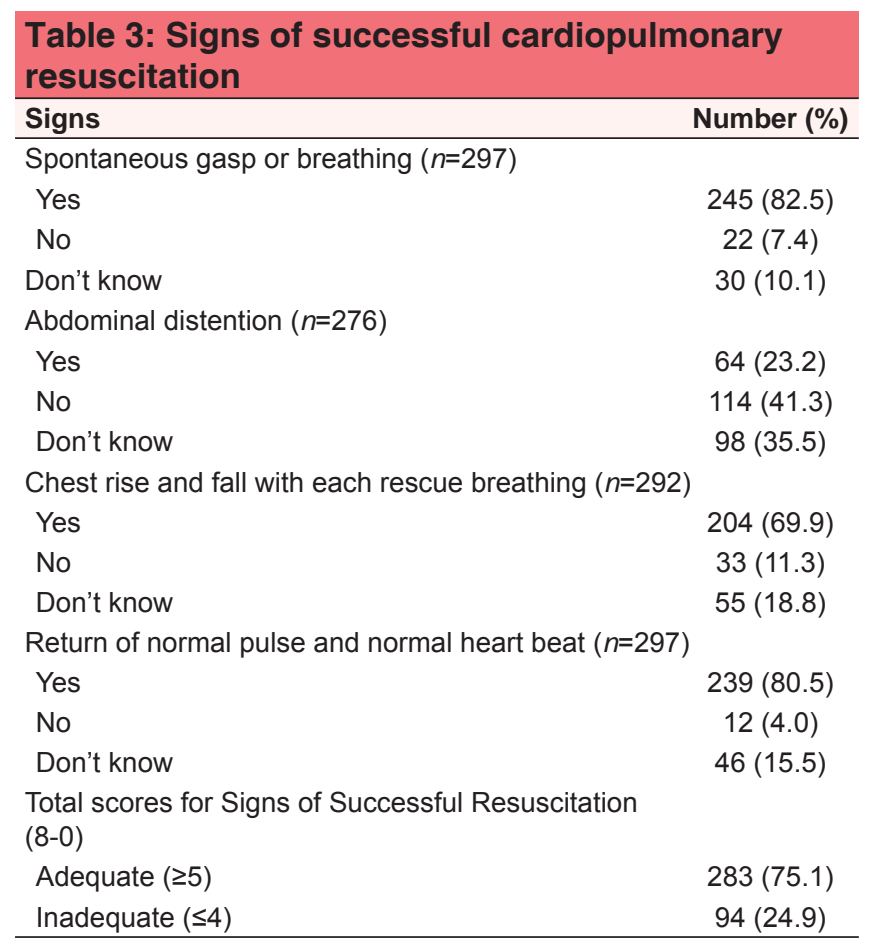

from all the years of MBBS, it can be inferred that final year students would be in a better position to do guesswork. Lack of knowledge about specific aspects of CPR/BLS reflects the truth, which is similar to the situation reported from the other studies referred to above [Tables 2 and 3].

Most (71\%) of the students wanted to avoid/were uncomfortable and about $50.2 \%$ were not confident of performing CPR/BLS [Table 4], although the total perception scores were higher (78.5\%). Similar findings have been reported from Europe. ${ }^{[4]}$

Very few $(18.9 \%)$ had undergone training. Low levels of training have been reported from Pakistan and UK. ${ }^{[8,5]}$ Comparison of students who had undergone training with those who had not undergone training [Table 5] revealed that training improved knowledge, but did not improve the confidence or alter the perceptions of the students. A study from Netherlands reported that only $38 \%$ of the clinical picture and diseases and $69 \%$ of the skills were mastered by the students after the training. ${ }^{[12]}$ As the skills deteriorated over a period of time, the students did not have confidence or have a favorable perception about CPR/BLS. Although training improves the knowledge, the loss of skills with time highlights the need to have repeated training over a period of time. This is possible only if the training is introduced at the beginning of the curriculum rather than in the final year, which is the current practice. As most $(93.7 \%)$ of the students wanted to learn about it from the beginning of the course, it reflects the 'felt needs' of the students.

This being a questionnaire based study; response bias might have been present. But, it is common to most of the questionnaire based studies. Furthermore, a certain amount of guesswork from

\begin{tabular}{|c|c|c|}
\hline Variable & $\begin{array}{l}\text { Number } \\
(\%)\end{array}$ & $\begin{array}{l}\text { Mean score } \\
\text { (Standard } \\
\text { Deviation) }\end{array}$ \\
\hline $\begin{array}{l}\text { I am confident of performing CPR } \\
\text { independently in an emergency } \\
\text { situation }(n=301)\end{array}$ & & $2.5(1.1)$ \\
\hline Strongly disagree & $62(20.6)$ & \\
\hline Disagree & $89(29.6)$ & \\
\hline Neutral & $89(29.6)$ & \\
\hline Agree & $45(15.0)$ & \\
\hline Strongly agree & $16(5.3)$ & \\
\hline $\begin{array}{l}\text { BLS training should be given in the first } \\
\text { and second years of MBBS }(n=367)\end{array}$ & & $4.4(0.8)$ \\
\hline Strongly disagree & $9(2.5)$ & \\
\hline Disagree & $7(1.9)$ & \\
\hline Neutral & $17(4.6)$ & \\
\hline Agree & $113(30.8)$ & \\
\hline Strongly agree & $221(60.2)$ & \\
\hline $\begin{array}{l}\text { General population needs to be trained } \\
\text { in BLS }(n=367)\end{array}$ & & $4.2(0.8)$ \\
\hline Strongly disagree & $4(1.1)$ & \\
\hline Disagree & $9(2.5)$ & \\
\hline Neutral & $44(12.0)$ & \\
\hline Agree & $156(42.5)$ & \\
\hline Strongly agree & $154(42.0)$ & \\
\hline \multicolumn{3}{|l|}{$\begin{array}{l}\text { Self-assessment of BLS knowledge on } \\
\text { a scale of } 10(n=300)\end{array}$} \\
\hline Score $\leq 5$ & $211(70.3)$ & $4.3(2.4)$ \\
\hline Score $\geq 6$ & $89(29.7)$ & \\
\hline \multicolumn{3}{|l|}{$\begin{array}{l}\text { Attitude toward a situation where a } \\
\text { person needs }\end{array}$} \\
\hline BLS $(n=358)$ & $36(10.1)$ & $2.2(0.6)$ \\
\hline Avoid the situation & $218(60.9)$ & \\
\hline Uncomfortable & $104(29.1)$ & \\
\hline \multirow{2}{*}{\multicolumn{3}{|c|}{$\begin{array}{l}\text { Comfortable } \\
\text { Total scores for perception about BLS/ } \\
\text { CPR }(28-0)\end{array}$}} \\
\hline & & \\
\hline Adequate ( $\geq 15$ ) & $296(78.5)$ & $17.7(4.7)$ \\
\hline Inadequate $(\leq 14)$ & $81(21.5)$ & \\
\hline
\end{tabular}

BLS=Basic life support, CPR= Cardiopulmonary resuscitation

\begin{tabular}{|c|c|c|c|}
\hline \multirow{2}{*}{$\begin{array}{l}\text { Total scores of various } \\
\text { components of knowledge } \\
\text { and perception } \\
\text { characteristics }\end{array}$} & \multicolumn{2}{|c|}{$\begin{array}{l}\text { Are you trained in } \\
\text { BLS (SD) }\end{array}$} & \multirow[t]{2}{*}{$\begin{array}{l}\text { 't' value } \\
(p)\end{array}$} \\
\hline & Yes mean & No mean & \\
\hline Indications for BLS/CPR & $1.67(0.47)$ & $1.60(0.46)$ & $0.4(0.97)$ \\
\hline $\begin{array}{l}\text { Response to a situation } \\
\text { needing BLS/CPR }\end{array}$ & $1.98(0.13)$ & $1.9(0.3)$ & $1.99(0.04)$ \\
\hline $\begin{array}{l}\text { Signs of successful } \\
\text { resuscitation }\end{array}$ & $1.98(0.13)$ & $1.87(0.33)$ & $2.54(0.01)$ \\
\hline Perception toward BLS/CPR & $1.95(0.22)$ & $1.93(0.25)$ & $0.56(0.58)$ \\
\hline
\end{tabular}

students could have resulted in higher levels of certain components of knowledge about CPR/BLS, as discussed earlier in the text. By 
exploring the awareness and perceptions of various components, it was possible to get an overall idea, thereby, reducing the impact of guesswork.

\section{CONCLUSIONS}

The students need to be taught and trained in the CPR/BLS early in the curriculum, to improve their knowledge. Repeated training would increase their confidence.

\section{ACKNOWLEDGMENTS}

We thank the College, Institutional Ethics Committee and and the Dean, who permitted us to conduct the study. We also thank the students. Without their participation, this study would not have been possible.

\section{REFERENCES}

1. Garg RH. Who killed Rambhor?: The state of emergency medical services in India. J Emerg Trauma Shock 2012;5:49-54.

2. Krishnan V. AlIMS to start specialized course in emergency medicine. Expressindia.com. 2009, Aug 03. Available from: http://www. expressindia.com/latest-news/aiims-to-start-specialised-course-in emergencymedicine/497292/[Last cited 2013 Mar 1].

3. Ruesseler $M$, Weinlich $M$. Simulation training improves ability to manage medical emergencies. Emerg Med J 2010;27:734-8.

4. Freund Y, Duchateau FX, Baker EC, Goulet H, Carreira S, Schmidt M, et al. Self-perception of knowledge and confidence in performing basic life support among medical students. Eur J Emerg Med 2013;20:145-6.
5. Mastoridis S, Shanmugarajah K, Kneebone R. Undergraduate education in trauma medicine: The students' verdict on current teaching. Med Teach 2011;33:585-7.

6. Chojnacki P, llieva R, Kolodziej A, Krolikowska A, Lipka J, Ruta J. Knowledge of BLS and AED resuscitation algorithm amongst medical students--preliminary results. Anestezjol Intens Ter 2011;43:29-32.

7. Businger $\mathrm{A}$, Rinderknecht $\mathrm{S}$, Blank R, Merki L, Carrel T. Students' knowledge of symptoms and risk factors of potential life-threatening medical conditions. Swiss Med Wkly 2010;140:78-84.

8. Zaheer $\mathrm{H}$, Haque Z. Awareness about BLS (CPR) among medical students: Status and requirements. J Pak Med Assoc 2009;59:57-9.

9. Chandrasekaran S, Kumar S, Bhat SA, Saravankumar, Shabbir PM Chandrasekaran V. Awareness of basic life support among medical, dental, nursing students and doctors. Indian J Anaesth 2010;54:121-6.

10. www.heart.org [internet]. 2010 American Heart Association Guidelines for CPR and ECC. American Heart Association [updated Sep 2012]. Available from: http://www.heart.org/idc/groups/heart-public/@wcm/@ ecc/documents/ downloadable/ucm_317350.pdf [Last cited on 2013 Feb 6].

11. Sharma R, Attar NR. Adult basic life support (BLS) awareness and knowledge among medical and dental interns completing internship from deemed university. NUJHS 2012;2:6-13.

12. Tan EC, Hekkert KD, van Vuqt AB, Biert J. First aid and basic life support: A questionnaire survey of medical schools in the Netherlands. Teach Learn Med 2010;22:112-5.

How to cite this article: Harsha Kumar HN, Upadhya PS, Ashok PS, Chowdari GA, Niranjan GM, Dinesh B. A cross-sectional study on awareness and perception about basic life support/cardiopulmonary resuscitation among undergraduate medical students from coastal South India. Int J Med Public Health 2013;3:146-50.

Source of Support: Nil, Conflict of Interest: None declared. 